\title{
A Case Report of Apert Syndrome in a Fifty-Eight Year Old Female
}

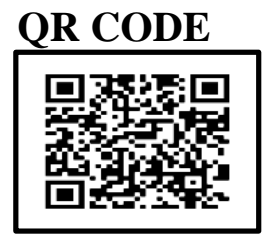

\section{POOJA GAUR*}

Defined as a rare type I acrocephalosyndactyly syndrome which is clinically characterized by dysmorphic facial features, craniosynostosis, and severe syndactyly of the hands and feet, Apert Syndrome represents an autosomal dominant inheritance which occurs due to the gene mutations in the receptors of the fibroblast growth factor. Oral lesions include tooth crowding, reduction in the size of the maxilla, impacted teeth, anterior open-bite, ectopic eruption, delayed eruption, thick gingiva and supernumerary teeth. The present case report describes a 58 year old female patient reported with the features of Apert's syndrome such as dysmorphic facial features, occular anomalies, syndactyly and oral features. The case was referred to a specialized centre of clinical care for further treatment.

KEYWORDS: Acrocephalosyndactylia, Apert syndrome, Craniosynostosis

\section{INTRODUCTION}

1906, Eugene Apert, a French Physician first described a rare type I acrocephalosyndactyly syndrome and termed it as "Apert syndrome". Its characteristic clinical features were severe syndactyly of the hands and feet, craniosynostosis and dysmorphic facial features. $^{2}$ This syndrome is autosomal dominant and is due to mutations in the fibroblast growth factor receptors (FGFR-2) gene at the locus 10q26.3.4

Most cases result from a genetic mutation observed in in the father and its prevalence at birth is $1: 65, \mathbf{O o o}^{2,6}$ and among offsprings, both genders are equally affected with this syndrome. ${ }^{5,6} \mathrm{~A}$ few sporadic cases of this syndrome are reported, and develop because of new mutations in genes. ${ }^{1}$

Cases with Apert syndrome document distinctive clinical phenotypic features in which the coronal sutures fuse prematurely (at less than 3 months) and this leads to a cone-shaped head known as acrocephalic (Cone-Shaped) coupled with a high prominent forehead and shortened antero-posterior diameter. The mid face is hypoplastic. Hypertelorism, down slanting palpebral fissures and proptosis are the occular anomalies. The nose is wide and short due to which the nasal bridge is depressed., ${ }^{1,2,5,7}$ Anomalies of the elbows and shoulders, skeleton, viscera, and impaired mental function due to central nervous system anomalies have been reported by previous studies. ${ }^{6,8}$

Oral signs include pseudocleft, high-arched palate, transverse, and sagittal maxillary hypoplasia, dental crowding, delay in dentition, ectopic teeth, disarrayed/crowded teeth. The mandible is generally normal in size, and pseudoprognatism can be seen. Symptoms related to CNS, cardiac, gastrointestinal, and urogenital system, and vertebral anomalies have been rarely been reported. ${ }^{9}$

Herein, we have aimed to present a 58-year-old female patient diagnosed with Apert syndrome based on clinical manifestations.

\section{CASE REPORT}

A female patient aged 58 years, reported to our OPD for regular dental check-up. The patient reported Apert syndrome and was the only case of her family.

The clinical triad of craniosynostosis, midface hypoplasia, and syndactyly of the hands and feet which is the characteristic of Apert Syndrome was present in the patient.

The patient had abnormal shaped skull which was characterised by a high, full forehead and a flat occiput which may be due to the premature closure of one or more of the joints (fissures) between the bones of the skull and early fusion of the coronal sutures representing Craniosynostosis.

The midface of the patient was incompletely developed. She had flat face, orbits were shallow, small nose, maxillary hypoplasia, and a narrow palate with a 
bifid uvula (Figure 1) along with cleft soft palate (Figure 2). The patient had varying forms of osseous and cutaneous syndactyly leading to fusion of fingers (Figure 3). Other clinical features which were present in the patient includes occular anomalies (proptosis, hypertelorism, slanting palpebral fissures \& right eye divergent strabismus) (Figure 4). Reduction in the size of the maxilla, anterior open-bite of the maxilla, supernumerary tooth, tooth crowding with ectopic tooth eruption were features present in oral cavity (Figure 5).

The patient was counselled properly, provided dental care and was referred to a specialized centre of clinical care for special needs patients.

\section{DISCUSSION}

Eugene Apert, in 1906, described the triad consisting of syndactyly of the hands and feet, dysmorphic facial features, and craniosynostosis as the characteristic clinical features of this particular syndrome. ${ }^{1}$ With mutations in the fibroblast growth factor receptors (FGFR-2) gene at locus 10q262,4, a rare autosomal dominant heritage was linked to the syndrome. The FGFR2 gene enables coding of a protein called fibroblast growth factor receptor -2 gene. This protein belongs to one of the four FGFRs that are responsible for the formation of blood vessels, wound healing, embryonic evolution, and regulation of cellular division, growth, and maturation in an individual.

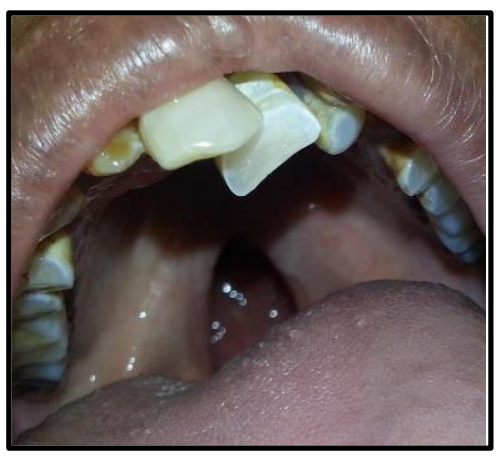

Figure 1. Bifid Uvula

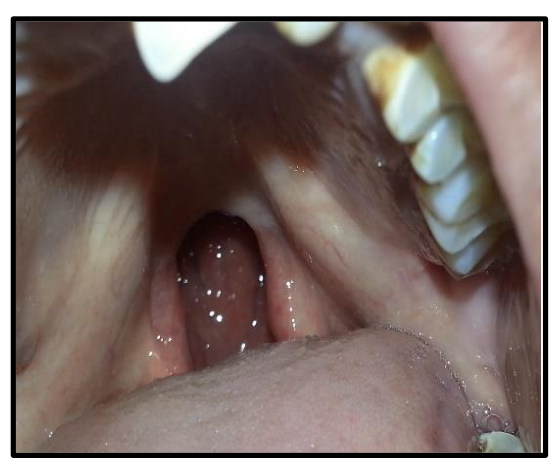

Figure 2. Cleft Soft Palate

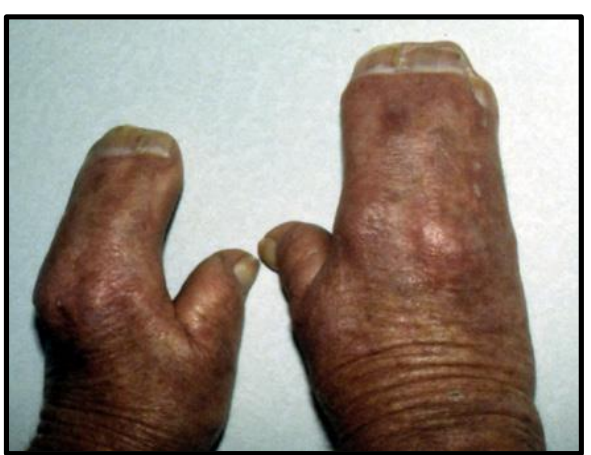

Figure 3. Syndactyly of the Hands

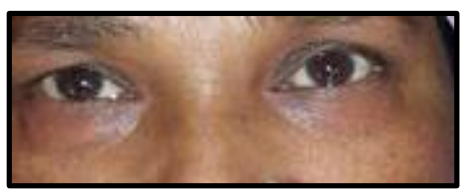

Figure 4. Proptosis, Slanting Palpebral Fissures and Right Eye Divergent Strabismus

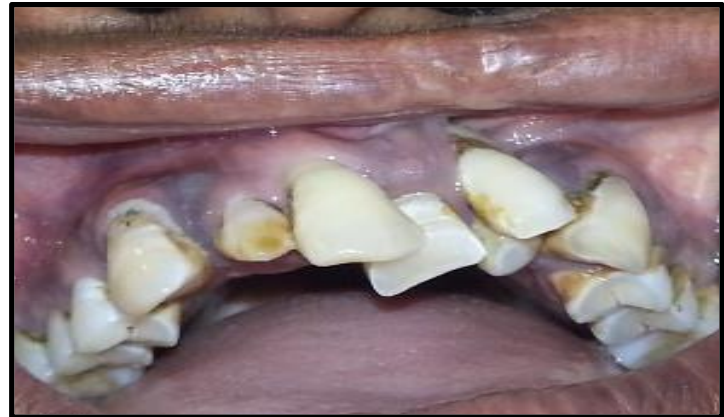

Figure 5. Supernumerary Tooth, and Crowding with Ectopic Tooth Eruption 
The well established clinical and oral features seen in this case report and are in agreement with the cases described in the literature. Clinically the syndrome is characterized by premature fusion of the coronal suture and hypoplastic midface. ${ }^{5,6}$

There have been instances in the literature where Anomalies of the elbows and shoulders, viscera, skeleton and central nervous system ${ }^{3,5}$ or abnormalities of the upper and lower respiratory tracts $^{1,3}$ have been reported in some affected individuals. However, the case reported here did not present any related complaint of these anomalies during clinical examination.

From a dental aspect, Combined orthodontic and periodontal treatment protocols are required for the effective clinical management to improve oral health in such patients.

\section{CONCLUSION}

For the effective planning and treatment of patinets suffering with Aperts syndrome, a multidisciplinary approach provided by dentists, plastic surgeons, neurosurgeons, ophthalmologists and geneticists is solicited.

\section{REFERENCES}

1. Koca TT. Apert syndrome: A case report and review of the literature. North Clin Istanbul. 2016;3(2):135-9. doi: 10.14744/nci.2015.30602

2. Bhatia PV, Patel PS, Jani YV, Soni NC. Apert's syndrome: Report of a rare case. J Oral Maxillofac Pathol 2013;17:294-7.

3. Freiman A, Tessler O, Barankin B. Apert syndrome. Int J Dermatol 2006;45:1341-3.

4. Dalben Gda S, das Neves LT, Gomide MR.Oral findings in patients with Apert syndrome. J Appl Oral Sci 2006;14:465-9.

5. Letra A, de Almeida AL, Kaizer R, Esper LA, Sgarbosa $S$, Granjeiro JM. Intraoral features of Apert's syndrome. Oral Surg Oral Med Oral Pathol Oral Radiol Endod 2007; 103: e38-41.

6. Surman TL, Logan RM, Townsend GC, Anderson PJ. Oral features in Apert syndrome: a histological investigation. Orthod Craniofac Res 2010;13:61-7.

7. Albuquerque MAP, Cavalcanti MGP. Computed tomography assessment of Apert syndrome. Braz Oral Res 2004;18:35-9.

8. Carneiro GV, Farias JG, Santos FA, Lamberti PL Apert syndrome: review and report a case. Braz J Otorhinolaryngol 2008;74:640.

9. Kumar GR, Jyothsna M, Ahmed SB, Sree Lakshmi KR. Apert's Syndrome. Int J Clin Pediatr Dent 2014;7:69-72.

Source of support: Nil, Conflict of interest: None declared

Cite this article as:

Gaur P. A Case Report of Apert Syndrome in a Fifty-Eight Year Old Female. Int Healthc Res J. 2020;3(11):352-354. https://doi.org/10.26440/IHRJ/0311.02318 